\title{
Does uncontrolled use of pseudoephedrine in puberty lead to a suicide attempt?
}

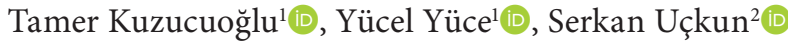 \\ ${ }^{1}$ Department of Anaesthesiology and Reanimation, Kartal Dr. Lütfi Kirdar Training and Research Hospital, Istanbul, Turkey \\ ${ }^{2}$ Department of Anaesthesiology and Reanimation, Manisa City Hospital, Manisa, Turkey
}

\begin{abstract}
Pseudoephedrine (PE) is commonly used in the treatment of influenza thanks to its sympathomimetic features. Our case was a 12-year-old American Society of Anesthesiologists (ASA) I female pediatric patient without known systemic disease. Her family reported that she was prescribed one bottle of cough syrup containing pseudoephedrine in a dosage of three teaspoons a day to treat upper respiratory tract infection (URTI) and that she attempted suicide by jumping from a height of 9 meters after she had drunk whole bottle of syrup at once. Her baseline examination at the emergency room was as follows: Glasgow coma score (GCS) 13, blood pressure (BP) 110/70 mmHg, heart rate (HR) 117 bpm, and peripheric oxygen saturation $\left(\mathrm{SpO}_{2}\right): 96 \%$. Due to low $\mathrm{SpO}_{2}$ and cognitive disorder, the patient was transferred to the intensive care unit (ICU) and emergency intubation was performed. She was connected to mechanical ventilation. Tomography revealed cerebral edema and anti-edema therapy was initiated. Arrhythmia and hypotension were not observed during ICU stay. Examination revealed flushing type erythema on the skin of the face and anterior trunk. The patient was extubated four days after admission and transferred to the related clinic six days after admission. Psychiatric consultation was requested. No significant disorder was encountered except for hallucinations. We attributed this irregular and negative outcome to toxic dose of ephedrine. We conclude that informing parents about the adverse effects of medication will provide them control and protect adolescents from the negative outcomes due to irregular and excessive ingestion of drugs.
\end{abstract}

Keywords: Intoxication, pseudoephedrine, suicide.

Intoxication cases are more common among females between 15 and 35 years of age who have suicidal intent. ${ }^{[1]}$ Adolescence is a period in which persons may experience intrapersonal and interpersonal conflicts. Medication is the leading factor among causes of suicide attempt and psychotropic agents are the most commonly used drugs for this purpose. ${ }^{[1,2]}$ It is stated that many agents cause toxic syndromes during psychiatric practice and exposure to these medicines may lead to increased mortality and morbidity. It is commonly observed that psychiatric findings and symptoms also accompany all of these syndromes. ${ }^{[3]}$

Today, medications containing ephedrine are widely used in the treatment of upper respiratory tract infection (URTI), while millions of people also use ephedrine for the treatment of obesity and to increase exercise performance. Recommended dosage for safe use in children is $4 \mathrm{mg} / \mathrm{kg} /$ day. However, when administered in higher doses; serious side effects such as arrhythmia, tachycardia, confusion, hallucination, headache, hypotension, erythema, and mortality may occur due to its sympathomimetic features. ${ }^{[4]}$ Our case had tachycardia, hallucination, and erythema on the skin without arrhythmia, confusion, or hypotension.

\section{CASE REPORT}

Our case was a 12-year-old American Society of Anesthesiologists (ASA) I, mean arterial pressure (MAP) I female pediatric patient who weighed $30 \mathrm{~kg}$ without known systemic disease. Based on her family's report, she was previously diagnosed as URTI by the medical center and

Received: June 09, 2020 Accepted: July 23, 2020 Published online: August 25, 2020

Correspondence: Yücel Yüce, MD. Kartal Dr. Lütfi Kırdar Eğitim ve Araştırma Hastanesi Anesteziyoloji ve Reanimasyon Kliniği, 34890 Kartal, İstanbul, Türkiye. Tel: +90 531 - 7943883 e-mail: dryyuce@gmail.com 
began using medication. The patient regularly used the prescribed medication for the first two days. On her third day of using medication, at about $6 \mathrm{pm}$, she drank almost the whole bottle of cough syrup containing pseudoephedrine (Actidem syrup $150 \mathrm{~mL}$ - $30 \mathrm{mg} / 5 \mathrm{~mL}$ [Glaxo Smith Kline, USA]) and she developed agitation, hyperkinesia, elementary type hallucinations, and balance disorder one hour after ingestion. Then she jumped off the third floor to the ground from a height of approximately 9 meters.

She was brought to the emergency service of the hospital and examination revealed Glasgow coma scale (GCS) score: 9, pupillary light reflex (PLR): positive/positive, blood pressure (BP): 110/70 $\mathrm{mmHg}$, heart rate (HR): 117/min, spontaneous breathing and bilaterally equal and normal respiratory sounds, and respiratory rate: $14 / \mathrm{min}$. She had no clinical symptoms of her urogenital and gastrointestinal tract. However, there was flushing type erythema on the skin of her face and anterior trunk. Since diffuse cerebral edema was encountered in tomography, she was transferred to the intensive care unit (ICU) and immediately intubated due to low $\mathrm{SpO}_{2}$. The patient was connected with mechanical parameters of $\mathrm{FiO}_{2}$ : $50 \% / \mathrm{O}_{2} /$ air, tidal volume: $5 \mathrm{~mL} / \mathrm{kg}$, peak inspiratory pressure (PIP): $15 \mathrm{~cm} \mathrm{H}_{2} \mathrm{O}$, Positive end-expiratory pressure (PEEP): $3 \mathrm{~cm} \mathrm{H}_{2} \mathrm{O}$. Four days after admission, the patient was extubated after achieving hemodynamic stability and on the sixth day she was transferred to the related clinic. Psychiatric consultation was conducted. No risk factors of suicide attempt or any predisposing stress-inducing effect except for hallucinations were detected.

\section{DISCUSSION}

Ephedrine is a member of the Ephedra group drugs and used as central nervous system (CNS) stimulant. Some authors have demonstrated that ephedrine increases the release of catecholamines by stimulating $\beta 1$ and $\beta 2$ receptors due to its indirect sympathomimetic effect. ${ }^{[4]}$ It is also stated that ephedrine also causes excitation and stimulation of the CNS by passing through CSF and thereby triggering epileptic seizures. However, the relatives of our patient relatives revealed that our case had no history of epilepsy or any similar systemic disorder. However, it has been determined that pseudoephedrine is a drug which shows an incidence of epileptic side effect also in the patients without epileptic complaints. It is also noted that pseudoephedrine is a medicine from Ephedra group drugs used as a decongestant in treatment of catarrhal and influenza infections and that it has ephedrine-like effects. ${ }^{[5]}$

Some studies have demonstrated that threshold for epileptic seizures decreases, thus increasing the incidence of epileptic seizures in people using dietary supplements containing Ephedra. ${ }^{[6]}$ In a same manner, other studies have shown that use of Ephedra group alkaloids together with caffeine may cause epileptic seizures. ${ }^{[7]}$ It has been noted that the incidence of epileptic seizures increases in those who ingest ephedra alkaloids together with caffeine and alcoholic beverages. ${ }^{[8]}$ Türedi et al. ${ }^{[8]}$ observed that cardiac arrhythmia developed two hours after ingestion of a medication containing $15 \mathrm{~mL} / \mathrm{kg} /$ bid pseudoephedrine for the treatment of influenza infection in a three-year-old pediatric patient without an accompanying disease. However, they also stated that arrhythmia improved after cessation of the drug without detecting other side effects and they consequently concluded that arrhythmia may develop due to administration of pseudoephedrine even in patients without previously known cardiac pathologies. In our case, arrhythmia was not encountered in electrocardiography (ECG) performed at baseline examination and during ICU follow-up.

Similarly, one study reported that urinary retention occurred when high doses of pseudoephedrine were administered for treatment of URTI in three-year-old pediatric patients. ${ }^{[9]}$ Backer et al. ${ }^{[10]}$ reported a case of a female patient who was found dead by her husband. Her cause of death was associated with ephedrine intoxication, Since ephedrine dosage exceeded normal therapeutic limits according to autopsy results, which revealed dissolved Ephedrine pills in her stomach and gas chromatography measurements detected $11 \mathrm{mg} / \mathrm{L}, 24 \mathrm{mg} / \mathrm{kg}, 14 \mathrm{mg} / \mathrm{kg}$ and $8.9 \mathrm{mg} / \mathrm{kg}$ ephedrine in her blood, liver, kidneys and brain, respectively. Some studies have reported that pseudoephedrine provokes bipolar disorder in the mixed period and it is included among the list of drugs that cause impaired mood balance. ${ }^{[10,11]}$ 
According to the patient's anamnesis after ICU admission, she was experiencing elementarytype hallucinations at the moment of the incident which developed in the manner of voice, lights, and loud noises. The reason leading to this fatal action made by our patient intentionally or unintentionally under intensive stress could not be fully clarified. We conclude that the adolescent patients who are prescribed Ephedragroup drugs may be more likely to commit suicide, especially in the puberty period, therefore there is a consensus that patients should be closely monitored; considering our patient, more invasive studies should be conducted to attribute pseudoephedrine as the accurate reason of such attempted suicide cases.

\section{Declaration of conflicting interests}

The authors declared no conflicts of interest with respect to the authorship and/or publication of this article.

\section{Funding}

The authors received no financial support for the research and/or authorship of this article.

\section{REFERENCES}

1. Mauri MC, Cerveri G, Volonteri LS, Fiorentini A, Colasanti A, Manfré S, et al. Parasuicide and drug selfpoisoning: analysis of the epidemiological and clinical variables of the patients admitted to the Poisoning Treatment Centre (CAV), Niguarda General Hospital,
Milan. Clin Pract Epidemiol Ment Health 2005;1:5.

2. Altınyazar V. Psikiyatride sık karşılaşılan toksik sendromlar. Psikiyatride Güncel Yaklaşımlar 2010;2:532-71.

3. Petekkaya S, Ayaz N, Dogan M, Oruc M, Oner BS, Gokturk C, Celebi A, et al. Suicidal Death from Pseudoephedrine Sulfate Overdose: A Case Report. Ulutas Med J 2015;1:119-21.

4. Berman JA, Setty A, Steiner MJ, Kaufman KR, Skotzko C. Complicated hypertension related to the abuse of ephedrine and caffeine alkaloids. J Addict Dis. 2006;25:45-8.

5. Haller CA, Benowitz NL. Adverse cardiovascular and central nervous system events associated with dietary supplements containing ephedra alkaloids. N Engl J Med. 2000;343:1833-8.

6. Kockler DR, McCarthy MW, Lawson CL. Seizure activity and unresponsiveness after hydroxycut ingestion. Pharmacotherapy 2001;21:647-51.

7. Doughty C, Walker A, Brenchley J. Herbal mind altering substances: an unknown quantity? Emerg Med J 2004;21:253-5.

8. Türedi Ö, Aypak C, Yüce A. Psödo Ephedrine kullanımına bağlı bir yan etki. Ventriküler aritmi. Eurasia J FAM Med 2012;1:7.

9. Soyer T, Göl IH, Eroğlu F, Cetin A. Acute urinary retention due to pseudoephedrine hydrochloride in a 3-year-old child. Turk J Pediatr 2008;50:98-100.

10. Backer R, Tautman D, Lowry S, Harvey CM, Poklis A. Fatal ephedrine intoxication. J Forensic Sci 1997;42:157-9.

11. Beşkardeş F, Özdemir S, Doksat K. Clinical approaches in bipolar disorders. New Symposium Journal 2006;1:23-33. 